\title{
Technical note: The two faces of the split-plot analysis of variance
}

\author{
ROBERT ZENHAUSERN \\ St. John's University, Jamaica, New York 11439
}

\begin{abstract}
Three separate sources provide incomplete information on the computer analysis of the split-plot factorial analysis of variance. Illustrative data are used to point out the mathematical and logical inconsistencies that arise from this deficiency.
\end{abstract}

A frequently voiced complaint regarding the area of data analysis is the lack of a standardized terminology. The term "split-plot" provides a clear example of this problem because it can refer to two entirely different designs. Hicks (1964), Snedecor (1956), and Sokol and Rohlf (1969) discuss one type of split-plot in which there are no repeated measures, and thus subjects is not a source of variance. The rationale for the design includes such considerations as (1) "to obtain more precise information..." (Sokol \& Rohlf, p. 363) and (2) "it may not be possible to completely randomize the order of experimentation..." (Hicks, p. 190). In general, the design is suggested as a way to increase precision and efficiency, to avoid randomization problems, and to decrease cost.

While this meaning of split-plot implies that the design is useful, but not necessary, the second meaning (the design much more useful for psychology) involves a necessary, as well as useful, design. This type of splitplot analysis of variance (Kirk, 1968; Winer, 1971) is a factorial design which includes repeated measures, as well as both between and within factors. A between factor is one in which a subject appears on only one level of an independent variable, while a within factor is one in which a subject appears on all levels of an independent variable. An example might be a design in which males and females are tested under several conditions. Sex is obviously a between factor, since a subject can appear in only one of the two categories. Conditions, on the other hand, is a within factor, since each subject is tested under each level. The variance estimates for the experimental conditions present no problem, but the measures of error depend on the kind of factor involved. The subject sums of squares is partitioned into the experimental sums of squares (sex) and the error sums of squares (subjects within groups) which is the appropriate error term for the between factor. The correct error term for the two within partitions (conditions and conditions by sex) is the interaction of conditions (the within factor) and the between error term (conditions by subjects within groups).

Three sources, an IBM technical manual (1970) and textbooks by Afifi and Azen (1972) and Ralston and
Table 1

Illustrative Data

\begin{tabular}{|c|c|c|c|c|c|}
\hline & & $\mathrm{B}_{1}$ & $\mathrm{~B}_{2}$ & $\mathrm{~B}_{\mathbf{3}}$ & $B_{4}$ \\
\hline$A_{1}$ & $\begin{array}{l}S_{1} \\
S_{2} \\
S_{3}\end{array}$ & $\begin{array}{l}10 \\
15 \\
14\end{array}$ & $\begin{array}{l}16 \\
13 \\
18\end{array}$ & $\begin{array}{l}9 \\
8 \\
6\end{array}$ & $\begin{array}{l}15 \\
19 \\
20\end{array}$ \\
\hline $\mathbf{A}_{2}$ & $\begin{array}{l}S_{4} \\
S_{5} \\
S_{6}\end{array}$ & $\begin{array}{r}9 \\
12 \\
11\end{array}$ & $\begin{array}{l}7 \\
7 \\
5\end{array}$ & $\begin{array}{l}17 \\
15 \\
14\end{array}$ & $\begin{array}{l}10 \\
13 \\
11\end{array}$ \\
\hline $\mathbf{A}_{3}$ & $\begin{array}{l}S_{7} \\
S_{8} \\
S_{9}\end{array}$ & $\begin{array}{l}8 \\
7 \\
4\end{array}$ & $\begin{array}{l}9 \\
5 \\
8\end{array}$ & $\begin{array}{l}10 \\
16 \\
14\end{array}$ & $\begin{array}{l}4 \\
3 \\
6\end{array}$ \\
\hline
\end{tabular}

Wilf (1960) consider only the first type of split-plot. When this procedure is applied to the second type of split-plot design, several serious problems arise. The between-error term these three sources recommend is the interaction of subjects by sex. Beyond being mathematically incorrect, it is logically unsound. Such an interaction would mean that a subject reacts differently when he (she) is in the male category than when he (she) is in the female category.

Illustrative data are presented in Table 1. Factor A is a between factor (e.g., grade level) and three subjects appear in each level of $A$, for a total of nine subjects in the whole design. Factor B is a within factor (e.g., conditions), under all levels of which each of the nine subjects appear, for a total of four scores for each subject. The correct split-plot analysis is shown in Table 2 .

An interesting problem arises concerning the number of subjects in the design, assuming that the A by Sub-

Table 2

Correct Summary of Split-Plot Analysis

\begin{tabular}{lrrrr}
\hline \multicolumn{1}{c}{ SV } & df & \multicolumn{1}{c}{ SS } & MS & \multicolumn{1}{c}{ F } \\
\hline Subjects & 8 & 211.72 & & \\
A & 2 & 198.72 & 99.36 & 45.78 \\
Subjects within groups & 6 & 13 & 2.17 & \\
B & 3 & 32.22 & 10.74 & 2.16 \\
A by B & 6 & 402.61 & 67.10 & 13.47 \\
B by Subjects within groups & 18 & 89.67 & 4.98 & \\
Total & 35 & 736.22 & & \\
\hline
\end{tabular}


Table 3

Incorrect Split-Plot Analysis of Variance Assuming Nine Subjects in the Design

\begin{tabular}{lrrrr}
\hline \multicolumn{1}{c}{ SV } & df & \multicolumn{1}{c}{ SS } & MS & \multicolumn{1}{c}{ F } \\
\hline Subjects & 8 & 211.72 & & \\
A & 2 & 198.72 & 99.36 & 171.31 \\
A by S & 16 & 9.28 & .58 & \\
B & 3 & 32.22 & 10.74 & 8.62 \\
A by B & 6 & 402.61 & 67.10 & 53.68 \\
(B by S) + (A by B by S) & 72 & 89.67 & 1.25 & \\
Total & 107 & 944.22 & & \\
\hline
\end{tabular}

jects interaction is the appropriate error term for the between factor. The first question that must be asked is how many subjects are in the experiment. One answer is nine. Table 3 represents the analysis that would result under this assumption. The most obvious discrepancy is that, although there are only 36 scores, there are 107 degrees of freedom and the total sums of squares has increased from 736.22 to 944.22 . The use of nine subjects assumes that each subject appears in each of the 12 $\mathrm{AB}$ conditions, for a total of 108 scores. This is clearly untenable.

If the assumption is made that only three subjects appear in the design, the resulting analysis would be represented in Table 4 . This, at least, does not overpartition. The design, however, is a randomized block factorial, not a split plot. Under this possibility, $S_{1}, S_{4}$, and $S_{7} ; S_{2}, S_{5}$, and $S_{8}$; and $S_{3}, S_{6}$, and $S_{9}$ are each considered a single subject. This, too, is untenable.

This problem first emerged when a student brought the results of an analysis to me and it was clear that something was wrong. After tracing down several sources, it was obvious that the problem had existed since at least 1960 . Since the IBM manual is in its fifth edition, it may have existed even before then. It is impossible to state how many studies have been incor-
Table 4

Incorrect Split-P1ot Analysis of Variance Assuming Three Subjects in the Design

\begin{tabular}{lrrrr}
\hline \multicolumn{1}{c}{ SV } & df & \multicolumn{1}{c}{ SS } & \multicolumn{1}{c}{ MS } & \multicolumn{1}{c}{ F } \\
\hline Subjects & 2 & 3.72 & & \\
A & 2 & 198.72 & 99.36 & 42.82 \\
A by Subjects & 4 & 9.28 & 2.32 & \\
B & 3 & 32.22 & 10.74 & 2.15 \\
A by B & 6 & 402.61 & 67.10 & 13.47 \\
(B by S) + (A by B by S) & 18 & 89.67 & 4.98 & \\
Total & 35 & 736.22 & & \\
\hline
\end{tabular}

rectly analyzed since that time, but hopefully the sources will soon be corrected. It should be noted that the main problem is not in the program or in its instructions but in the user. There should be some warning, however, that the term split-plot can have more than one meaning, and the user should ascertain which of the two is appropriate to his data.

\section{REFERENCES}

Afifi, A., \& Azen, S. Statistical analysis: A computer oriented approach. New York: Academic Press, 1972.

Hicks, C. Fundamental concepts in the design of experiments. Holt, Rinehart, \& Winston: New York, 1964.

IBM Application Program. System/360 scientific subroutine package [version III]. Programmers Manual (5th ed.). White Plains, N. Y: 1970.

KIRK, R. Experimental design procedures for the behavioral sciences. Belmont, Calif: Brooks/Cole, 1968.

Ralston, A., \& Wilf, H. Mathematical methods for digital computers. New York: Wiley, 1960.

Snedecor, G. Statistical methods. Ames, Iowa: Iowa State University Press, 1956.

Sokol, R., \& Rohlf, J. Biometry. San Francisco: Freeman, 1969.

WINER, B. Statistical principles in experimental design (2nd ed.). New York: McGraw-Hill, 1971.

(Received for publication October 13, 1976.) 